\title{
The Nature of Child Computer Interaction
}

\author{
Janet C Read \\ University of Central Lancashire \\ Preston, PR1 2HE \\ jcread@uclan.ac.uk
}

\author{
Mathilde M. Bekker \\ P.O. Box 513, 5600 Eindhoven \\ University of Technology MB Eindhoven \\ m.m.bekker@tue.nl
}

\begin{abstract}
This paper analyses the field of Child Computer Interaction $(\mathrm{CCl})$. Beginning with an historical look at this field, and identifying some of the key moments in its development, the work then brings together reflection from experience, and knowledge from literature, to describe and explain the nature of Child Computer Interaction. In this process, the authors highlight the key differences that set $\mathrm{CCl}$ apart from Human Computer Intraction $(\mathrm{HCl})$ and explore the extent to which both similarities and differences impact on the methods and approaches needed for research and practice in $\mathrm{CCl}$. Key differences that are identified are the rate of change of children, the involvement of adult participants in children's interactions, the contexts in which children use computer technology, and the underlying cultural and societal assumptions about technology and children that determine what is good for children and what has value.
\end{abstract}

\section{Children, Interaction, Child Computer Interaction, Theory, Frameworks.}

\section{INTRODUCTION}

The Human Computer Interaction $(\mathrm{HCl})$ Community is forever changing. Initially emerging from the ergonomics and socio-technical research agendas and providing guidance and research into work based systems, the $\mathrm{HCl}$ community has always been open to changes in the people and processes that are under its remit. Changes in the way people communicate, learn, work and play have all impacted on the $\mathrm{HCl}$ agenda. As an example, research is more often than not now focused on user experience rather than on usability, on playfulness rather than on productivity and on communication rather than control.

Child Computer Interaction $(\mathrm{CCl})$ is a research area within $\mathrm{HCl}$ around that is relatively new - it grew from pockets of work, mainly driven from interests in technology use within education and schools, in its own early years, before developing into an identifiable community within the $\mathrm{HCl}$ space which is beginning a process of maturing into its own discipline with its own associated methods and solutions.

This paper takes a broad look at $\mathrm{CCl}$, synthesises what is currently known about it, identifies its specialities and its foci and defines the nature of it for the benefit of future research endeavour.

\subsection{Early Days of CCI}

It is difficult to pinpoint when $\mathrm{CCl}$ began; it could be justly argued that the first major works in this area were those by Papert (1980) and later Kafai (1990), Resnick (1991) and Ackermann (1991)). In the late ' 80 s and through the ' 90 s there was considerable work being done in the general area of children's abilities to use computers - much of this was being published, not only in $\mathrm{HCl}$, but also in journals about computers and education; one example is the work on children's input abilities by Revelle and Strommen (1990). In the same time frame there were many studies looking at how children dealt with reading from screens and the possibilities for recognition, especially speech recognition were being heavily investigated (Mills and Weldon 1987; Mostow, Hauptmann et al. 1995).

A realisation that there were different influences (beyond school based education) at play in $\mathrm{CCl}$, that were going to add more value to the possibilities around computers and children, was probably first articulated in Soloway, Guzdial et al. (1994)'s paper entitled 'Learner Centred Design' which identified, among other things, the role that adults have in the use of, and access to, 
technologies for children. Around the same time, taking inspiration from Papert, innovative work by Bers and Cassell (1998) also played a major influence in understanding how technology could be used to augment and improve activities around children's language.

Child Computer Interaction therefore began to move out of school contexts and enthusiasm for it was significantly increased towards the end of the $20^{\text {th }}$ century with the publication of the two books by Druin, (Druin and Solomon 1996), (Druin 1999) and the development, also headed up by Druin, of the Chi-kids community as a part of ACM SigChi. These, together with an influential publication by Hanna, Risden et al. (1997) that outlined how best to involve children in usability evaluation, lead the field to broaden its scope to consider the direct involvement of children in the design and evaluation of their own technologies.

\subsection{Child Computer Interaction in the 21st Century}

In 2003, Bruckman and Bandlow wrote a chapter on ' $\mathrm{HCl}$ for Kids' in the Handbook of Human Computer Interaction and around the same time, a research group in Eindhoven, NL had the foresight to propose an initial research workshop on Interaction Design and Children (Bekker, Markopoulos et al. 2002) This event, attended by over 100 people, was a huge success and as a result, in the following year (2003), the inaugural conference in Interaction Design and Children was held in Preston, UK. This conference then moved across to the United States where it was hosted by the University of Maryland and it has since been an annual event taking place in Boulder, CO, US, Aalborg, DK, Tampere, FI, Lake Como, IT, Chicago, MI, US, Barcelona, ES and Michigan, $\mathrm{OH}$, US in 2011.

The IDC conference is not the only venue for researchers in $\mathrm{CCl}$ - over the past ten years papers and events have been published or held at all the major $\mathrm{HCl}$ venues, including British $\mathrm{HCl}$. The popularity of $\mathrm{CCl}$ can be seen in Figure 1, which shows the increasing number of $\mathrm{CHI}$ papers that have included 'children' in their content.

It is worth mentioning here that Child Computer Interaction and Interaction Design and Children have become two terms by which the field is described and these terms are often, but not always, used interchangeably; the purist may say that IDC is more concerned with design and $\mathrm{CCl}$ is more focussed on theory.

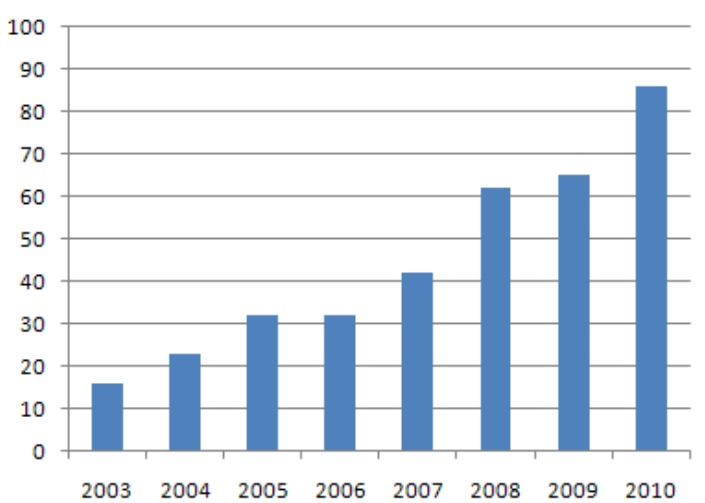

Figure 1 - Number of papers published at $\mathrm{CHI}$ with 'children' in their content

Research work since 2000 has largely focussed on better understanding, and confirming or refuting, the several ideas that were touted in the earlier years and on investigating the different contexts of children and technology use. There has been a recent focus on designing for children using new technologies (Chipman, Druin et al. 2006), (Robins, Dautenhahn et al. 2008), (Paive, Chaves et al. 2003) on designing new educational solutions (Rogers, Scaife et al. 2002), (Read, MacFarlane et al. 2001), on designs for play and sociability (Stromberg, Vaatanen et al. 2002; Brederode, Markopoulos et al. 2005) (Pares, Durany et al. 2005) and on the investigation and refinement of ideas to enable children to be better involved in design and evaluation activities (Bekker, Beusmans et al. 2002; Markopoulos and Bekker 2002; Markopoulos, Barendregt et al. 2005; Kelly, Mazzone et al. 2006; Edwards and Benedyk 2007; Sluis-Thiescheffer, Bekker et al. 2007; Xu, Read et al. 2007).

The community is starting, therefore, to define itself. In 2009 researchers in this area created an International iFIP TC13 group (www.idcsig.org) and are currently proposing their own journal. Three special edition journals (and one under production) have been produced and several courses on Child Computer Interaction have been held at $\mathrm{CHI}$, Interact and IDC. At least one university offers an MSc in Child Computer Interaction and $\mathrm{CCl}$ is reported to be included in several $\mathrm{MSc} \mathrm{HCl}$ courses across globe. The current community is estimated to comprise in the region of 400 individuals - this would include around $150 \mathrm{PhD}$ students and research assistants.

For these people, and for the research community in $\mathrm{CCl}$, some move towards a definition, or at least an explanation, of the field, feels rather overdue. This paper, theoretical in nature, seeks to address this failing by examining the nature of $\mathrm{CCl}$, by exploring, in a structured process, how it differs from $\mathrm{HCl}$, and by proposing areas where future work might be well situated. 
The method used is to firstly examine one means by which $\mathrm{HCl}$ is defined and then by mapping $\mathrm{CCl}$ onto that definition, whilst also looking around $\mathrm{CCl}$ to see what additional perspectives can be taken from theoretical works by researchers. This knowledge is then synthesised into an embryonic framework for understanding what $\mathrm{CCl}$ is about and where it is going.

\section{CCI EXPLORED IN HCI TERMS}

It is unsurprising that the Child Computer Interaction Community has been slow to clearly articulate what it means by $\mathrm{CCl}$. Its' forefather, $\mathrm{HCl}$, is only weakly defined even after many many years of being in existence. The most widely used definition of $\mathrm{HCl}$ is this one from the Association of Computing Machinery which states:

Human-computer interaction is a discipline concerned with the design, evaluation and implementation of interactive computing systems for human use and with the study of major phenomena surrounding them (ACM SigChi)

From this definition it is relatively easy to extrapolate a general definition of $\mathrm{CCl}$ that would be (defn 1):

Child computer Interaction is a discipline concerned with the design, evaluation and implementation of interactive computing systems for children's use and with the study of major phenomena surrounding them

On its own, this definition is not especially useful as it merely gives an overall flavour of the subject and indeed is not all that helpful in determining the differences between the two disciplines that, with this glance, appear to be simply the fact that the human is now a child.

\subsection{Defining Child Computer Interaction}

Replacing humans with children is a common theme in definitions of $\mathrm{CCl}$. As an example, Read (2005) defined it as 'that part of Human Computer Interaction where the humans are children'. The use of the term children is not unambiguous; in terms of the UN, stated in the UN Convention on the Rights of the Child, a child is any person aged less than 18 . This is probably the most expansive definition of a child and the $\mathrm{CCl}$ community have tended to gravitate around a general understanding of children being aged from around three to sixteen although most of the work in $\mathrm{CCl}$ focuses on children aged between five and eleven. There have been very few studies that have concerned themselves with children aged under three and design for, and accessing, children aged between 16 and 18 is naturally confusing given the different legislations around the world which leave this group in some sort of limbo

In the article, the ABC of CCl, Read (2005) proposed that the necessity for a special area of study for $\mathrm{CCl}$, as opposed to it being simply a subset of $\mathrm{HCl}$, was associated with three key differences between children and adults: namely Activities, Behaviours and Concerns. In exploring this assumption, Read stated that children do different activities with computers than adults do, they behave differently around computers than adults do and the concerns of children are, not for example, with usability but are, about something much different.

\subsection{Mapping $\mathrm{CCl}$ to $\mathrm{HCl}$}

As indicated earlier, possibly the tightest and most used definition of $\mathrm{HCl}$ is that proposed by the ACM SigChi curriculum for $\mathrm{HCl}$. This definition is clearly a teaching centred definition and is not specifically concerned with research but, in stating what might be taught, it also scopes out, in a loose way, what might also be researched. The ACM SigChi curriculum refers to 'the nature of $\mathrm{HCl}$ ' by mapping out its essential components. It is presented in five sections with the top section being $(\mathrm{N})$ the nature of human-computer interaction and the four supporting sections being:

- (U) the use and context of computers

- (C) computer system and interface architecture,

- (D) the development process

- $(\mathrm{H})$ the human characteristics

The first of these five is at the heart of the problem being considered in this paper - to determine what is the nature of $\mathrm{CCl}$. This is about questioning what $\mathrm{CCl}$ really is made up of and will be answered in later sections of this paper. The other four areas each have meanings in $\mathrm{CCl}$ that can align with, but are different from, the meanings for $\mathrm{HCl}$. In the next four sections, using citations from the literature on $\mathrm{CCl}$, these similarities and differences are explored.

Use $(U)$ and Context of Computers with Children A discussion of contexts can be framed around the activities that children carry out around computers. When children use computers they are generally focussed on play, on learning or on communicating.

In terms of play, this is a relatively new area for $\mathrm{CCl}$. Gameplay and general play is currently being enthusiastically studied in $\mathrm{CCl}$ especially with 
regard to mobile, portable and outdoor systems (Wakkary and Hatala 2006; Zuckerman, Parés et al. 2008; Marti, Pollini et al. 2009). A lot of work on play is now, however, in the arena of serious games and collaborative and fun based learning (Budd, Madej et al. 2007), (Khaled, Barr et al. 2009),

Education (or learning) and children have always gone hand in hand. In the early days a lot of work was focussed on the design and implementation of educational activities especially focussing on the promise of computer based tutoring (Newell, Boothe et al. 1992), (Haas and Hayes 1986) and was, naturally, mainly situated in school contexts with desktop computers (Fisher 1994). Designing for educational contexts is still a high priority for the community.

Associated with learning, and broaching into communication, there is current a wave of interest in pro-social systems that tutor children about lifestyle choices like, for example, healthy eating and taking exercise (Revelle, Fenwick-Naditch et al. 2010). Systems that specifically enable communication are also very current, some of these bring children and their families together (Yarosh, Chew et al. 2009) and others are intended to promote inclusion and connectivity across children groups (Teh, Cheok et al. 2008).

Future developments in this area are difficult to predict but for play, the possibilities of fantasy play and play in augmented outdoor spaces is tantalising. In areas of education, as Al improves and positioning systems become widely accepted, it is not inconceivable to imagine children learning as they traverse streets and as computing becomes more and more ubiquitous recommender systems - that, for instance, suggest activities based on context and location, and communicate these activities to others in a social mish mash are all possibilities.

\section{Computer (C) System Architecture}

When looking at systems in the regard of children, one focus has to be on the technology. Children's technology might be desks (in school), mobile, or tangible, children's products need to be designed for their behaviours in these different situations. A well-designed interface is able to work with the behaviours of the user.

In early years systems were all desk based and the key aspects of interest were around dialogue, metaphors and graphics. In the past, much of the work in this space was concerned with how the look of the computer screen affected the interaction. Work on readability of screens, (Bernard, Mills et al. 2001) and on the look and presentation of the design of interfaces was studied in considerable depth (Sedighian and Sedighian 1997). (Jacobson 1995). Clearly as the technology moves away from the desktop, some of these works need to be revisited. Some of the current work in this space is still about screen design but the design of information is also being studied by dint of how children might find it (Druin, Foss et al. 2010) and how children might understand It (Bilal and Kirby 2002). As the interface opens to a world of information, work in this area clearly needs to continue.

Based on the contents of recent conferences and the most recent research papers, a typical $\mathrm{CCl}$ system is likely to be a semi educational game on a handheld or tabletop device (Marco, Cerezo et al. 2009).

In understanding mobile and tangible systems, one key problem, if that is the right word, for the design of computer system architecture to support children's behaviours is that children are constantly adapting to the interface. What was a problem for children five years ago may not be a problem now as children learn alongside computer systems and acquire skills that children of their age previously did not have. An example here is the 'search' process where it is apparent that children 'learn' to adapt to the Google search process.

Areas for study in the future may be associated with the ubiquity of computer systems in children's lives and may be more concerned with their relationships with the computer, the data, and the information - rather than solely focussed at the interface. Key areas for future study include the security and trust that is built into computer systems and understanding how systems should be designed to best support children.

\section{The Development (D) Process}

Encircling the activity that drives good interaction design there is the set of processes or methods that 'do' $\mathrm{HCl}$. These are associated with the concerns for children's well being during the evaluation, design, and research of computer interfaces.

Understanding how best to evaluate computer interfaces for children was not especially studied in the early days of $\mathrm{CCl}$, but it is now an area where there have been many studies proposing new methods for evaluating technologies (with and without children), (Kersten-Tsikalkina and Bekker 2001; Read, MacFarlane et al. 2002; Hanna, Neapolitan et al. 2004; Zaman and Abeele 2010). There have also been many new design methods (Druin 1999; Taxen, Druin et al. 2001; Read, Gregory et al. 2002; Robertson 2002). A key focus in current work has been to start to unpick the differences between children and adults in respect, 
for instance, of their views on what makes a good product. Children have been shown to have different concerns than adults, seeing fun and playability as being more important in technology choice than ease of use. As an example, the technology acceptance model (Hassenzahl, Platz et al. 2000) has been shown to potentially need a different interpretation when applied to children's products because clearly children are not made to use technology and their technologies are not task based (Read 2008).

In terms of understanding how best to carry out research in $\mathrm{CCl}$, a methodological workshop at Interact in (Markopoulos, Höysniemi et al. 2005) contributed several ideas and provoked some discussion around ethics (Rode 2009) and explored the (safety and principles of working with children in schools (Rode, Stringer et al. 2003).

Future work in this space will no doubt continue to look at ways to better evaluate and design children's interactive products but aligned with this it is anticipated that there will grow a social conscience around the design of and evaluation of children's technology that may want to look more carefully at the value and ethics of child involvement in the development process and of the value and purpose of products that are designed.

\section{Children $(H)$ Characteristics (Abilities)}

Human characteristics as applied to children are clearly different from those studied with adults. In the ABC paper (Read 2005), Read failed to focus on this - the abilities of the children. $\mathrm{CCl}$ clearly has to take specific account of the physical sizes and abilities, memory and processing abilities and the ability of children to read but it has the additional task of understanding the changes and the diversity in this space - these are both problems that are much less apparent in $\mathrm{HCl}$ where the user group is more static in terms of development and more homogenous in terms of abilities (Krasnor and Pepler 1980).

Early work in this area was focussed around the design of input technologies and the ability of children to manage the physical aspects of the technology (Strommen 1994), (Joiner, Messer et al. 1998); these studies, generally took account of child development; Other work included the study of website design for children by Gilutz and Nielsen (2002) that focussed on abilities like reading and considered how to design, for example, for children who were poor readers.

More recent work in the input technology space has become concerned with the new possibilities, for instance multi touch (Harris, Rick et al. 2009) but there are still studies looking at how children interact with physical devices (Hourcade, Bederson et al. 2004), in 2D situations (Buisine and Martin 2005) and with mobile devices (Siek, Rogers et al. 2005).

Future work is likely to still look at physical abilities but should also focus on developmental studies that ensure well-designed products (Bekker and Antle 2011). It is possible that as systems become more and more complex, and children become computer users at an earlier and earlier age, that children's abilities to interact with them and understand the meanings associated with them, will change - but one challenge for the future will be to make complex systems continuously accessible to children by the use of predictive, smart and personalisable input and by the use of output systems that grow and adapt with the child. Brain computer interaction is one example in this space of an area ripe for future study.

\section{CCI DEFINING ITSELF}

The situation of children's uses of technology is primarily at school or the home. Children spend almost half their waking time in school and most of the remainder is spent at, or around, home. Thus the context of use is more often around the family or friends. Where children use computers for communication, this is more about social chatter and shared playing and learning where the users are children.

For children, interaction is more about the nature of fun and the nature of learning rather than the nature of work, good interaction will understand not how the computer fits in with the regular world of work, but how it fits with the world of play and education. More than anything else - children's computing is discretionary - the computer dissolves into the current activity.

$\mathrm{CCl}$ researchers have reflected on the field in several framework papers. Three of the most recent are explored in the next section.

\subsection{Frameworks that inform}

One of the earliest recent frameworks is the one for learning that is presented in the 2002 paper by Rogers, Scaife et al.. This framework, summarised in table 1, divides the conceptual space for learning into four kinds of transform types, coupling different combinations of actions and effects, that vary along physical and digital dimensions (see Table 1).

When considered in terms of Activities, Behaviours, Concerns and Abilities, this framework is mostly aligned to Abilities but is also about Behaviours. It seeks to identify what is likely to be unfamiliar and familiar to children. It serves as a good example of the observation, made earlier in this paper, that for 
a single age group of children, behaviours may cause abilities to change over time. As an example, in the age of Wii games, children may now (in 2011 as opposed to then 2002) not be unfamiliar with physical actions having digital effects.

Table 1 - Transform Type and children's existing level of familiarity with them

\begin{tabular}{|l|l|}
\hline \multicolumn{1}{|c|}{ Transform type } & \multicolumn{1}{c|}{ Level of familiarity } \\
\hline $\begin{array}{l}\text { Physical action to Physical } \\
\text { effect (PPt) }\end{array}$ & Highly familiar \\
\hline $\begin{array}{l}\text { Physical action to Digital } \\
\text { effect (PDt) }\end{array}$ & Unfamiliar \\
\hline $\begin{array}{l}\text { Digital action to Digital } \\
\text { effect (DDt) }\end{array}$ & Familiar \\
\hline $\begin{array}{l}\text { Digital action to Physical } \\
\text { effect (DPt) }\end{array}$ & Highly unfamiliar \\
\hline
\end{tabular}

The second framework considered here is the PLU model proposed by Read (2004) in Markopoulos, Read et al. (2008). In terms of Activities, Behaviours, Concerns and Abilities, the PLU model (shown in Figure 2) is primarily focussed on Activities but also eeks into the Concerns of children in relation to what is important in each of these spaces. The PLU model suggested that children's activities can be mapped in a 3D space of Play, Learning and Use and that the position of an activity, in this space, should determine how it should be evaluated. Clearly the aspects shown in The PLU model, for evaluation, are adult centred and the Concerns of the children may be all about fun, or all about challenge (for example) and so in this regard, the model only has limited value.

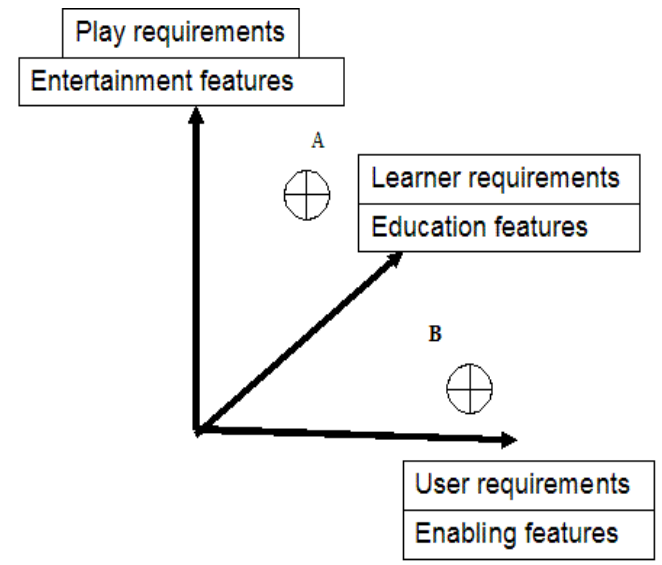

Figure 2 - PLU model

The third framework of interest is Alissa Antle's CTI framework (Antle 2007). When mapped against Activities, Behaviours, Concerns and Abilities this framework, is primarily associated with Behaviours but may also associate with Abilities. This framework highlights five areas - two of these are spaces, the other three are mappings. The spaces in this framework could be considered to be the environment within which $\mathrm{CCl}$ takes place - here there is a requirement for a space for action and a space for friends. The framework additionally concerns the interaction space by highlighting three mappings that have to be right for robust interaction - the mappings of meaning, of appearance and of behaviours. In consideration of the latter, the author of this framework makes a very strong (and highly appropriate) case for designers to carefully consider the developmental stages of the children.

\subsection{Outside Influences on $\mathrm{CCI}$}

As has been alluded to earlier, $\mathrm{CCl}$ is perhaps a little 'bigger', or maybe simply more 'messy' than $\mathrm{HCl}$ in terms of the outside influences. Indeed, these outside influences may be almost inside influences. Two key actors on what children do with technologies, how they interact with technologies, and which technologies are designed for them are the adults with which they interact daily (mainly parents and teachers) and the adults who determine the culture and society (maybe the policy makers) in which they live.

\section{Adults and Children}

In considering the full nature of $\mathrm{CCl}$ however, it is imperative to understand that the field is cluttered in that it has within it, a set of influential adults. These adults may determine what the child uses, may assist in its use and may design the look and feel of the interface. The understanding of, and the design for adult influences on $\mathrm{CCl}$ is a major consideration for the field. In the choices of technologies used the adults generally hold the 'purse strings' and are often influenced by information that is nothing to do with usability or suitability and can be a mixture of marketing hype and peer pressure. Parents are known to find selection of interactive technology for children to be difficult. Some of the tensions between adults and children are considered in Rode (2009) but in $\mathrm{HCl}$ and $\mathrm{CCl}$ such studies are rare- notable exceptions are a study of the influences of school systems in Rode, Stringer et al. (2003), a discussion of shared evaluations in Markopoulos, Barendregt et al. (2005) and a study of teachers as evaluators in Pardo, Vetere et al. (2006). In terms of shared interactivity, very few papers have really took hold of the interactivity when there are children and adults together at the computer; designs for adults and children are proposed in Huggy Pajamas (Teh, Cheok et al. 2008), and mediated work is described in Klein, Nir-Gal et al. (2000) and Buisine and Martin (2005).

\section{Children and Society}

Opinions around technologies for children vary across the globe. Even within countries, there are divisions about what is 'good' for children. 
In describing the nature of $\mathrm{CCl}$ it is therefore important to note how the other people in the $\mathrm{CCl}$ space influence the Activities and Concerns of the Children during their interactions with and their evaluations and designs of, software. Taking all that into account, a new definition (defn2) is proposed and The Nature of $\mathrm{CCl}$ is therefore considered to be:

a study of the Activities, Behaviours, Concerns and Abilities of Children as they interact with computer technologies, often with the intervention of others (mainly adults) in situations that they partially (but generally do not fully) control and regulate.

\section{CONCLUDING THOUGHTS}

This paper has presented a first attempt to understand the filed of Child Computer Interaction. The method used, beginning with the ACM SigChi definition for $\mathrm{HCl}$ will have necessarily affected, to some extent, the way the work evolved. Whether the same set of four key features would have been distilled during a different approach is not known.

Despite these imitations, the authors consider that this paper will provide a framework on which others may build, will provide a discussion document that will benefit the field and will be instructional to new researchers seeking to understand this area of work.

Future work will continue to explore this topic, will seek to better understand the influences of parents, teachers and society and will seek to augment theoretical understanding with practical guidance.

\section{REFERENCES}

Ackermann, E. (1991). The agency model of transactions: Towards an understanding of children's theory of control. Psychologie genetique et sciences cognitives. . J. Montangero and A. Tryphon. Geneve: , Fondation ArchivesJ ean Piaget.

Antle, A. N. (2007). The CTI Framework: Informing the design of tangible and spatial interactive systems for children, . First International Conference on Tangible and Embedded Interaction, Baton Rouge, ACM.

Bekker, M., J. Beusmans, et al. (2002). KidReporter: a method for engaging children in making a newspaper to gather user requirements. IDC2002, Eindhoven, NL, Shaker.

Bekker, M. M. and A. N. Antle (2011). Developmentally Situated Design (DSD): Making Theoretical Knowledge Accessible to Designers of Children's Technology. CHI'11, Vancouver, CA,
Bekker, M. M., P. Markopoulos, et al., Eds. (2002). Interaction Design and Children. Maastricht, NL, Shaker Publishing BV.

Bernard, M., M. Mills, et al. (2001). Which fonts do children prefer to read online? Usability News, SURL. January: 1.

Bers, M. and J. Cassell (1998). "Interactive storytelling systems for children: using technology to explore language and identity." Journal of Interactive Learning Research 9: 183 - 215.

Bilal, D. and J. Kirby (2002). "Differences and similarities in information seeking: children and adults as Web users " Information Processing \& Management 38(5): 649 - 670.

Brederode, B., P. Markopoulos, et al. (2005). pOwerball: The design of a novel mixed-reality game for children with mixed abilities. IDC 2005, Boulder, Colorado, ACM Press.

Bruckman, A. S. and A. Bandlow (2003). HumanComputer Interaction for Kids. The Human Computer Interaction Handbook. J. A. Jacko and A. Sears. Mahwah, NJ, Lawrence Erlbaum: 428 - 440. Budd, J., K. Madej, et al. (2007). PageCraft: Learning in Context: A tangible interactive storytelling platform to support early narrative development for young children. IDC2007, Aalborg, Denmark, ACM Press.

Buisine, S. and J. C. Martin (2005). Children's and Adults' Multimodal Interaction with 2D Conversational Agents. CHI'2005, Portland, USA, ACM Press.

Chipman, G., A. Druin, et al. (2006). A case study of Tangible Flags: A collaborative technology to enhance filed trips. IDC2006, Tampere, Finland, ACM Press.

Druin, A. (1999). Cooperative inquiry: Developing new technologies for children with children. $\mathrm{CH} 999$, ACM Press.

Druin, A., Ed. (1999). The Design of Children's technology. San Francisco, CA, Morgan Kaufmann Publishers, Inc.

Druin, A., E. Foss, et al. (2010). Children's roles using keyword search interfaces at home. $\mathrm{CHI}$ '10, Atlanta, ACM Press.

Druin, A. and C. Solomon (1996). Designing Multimedia Environments for children, John Wiley and Sons Ltd.

Edwards, H. and R. Benedyk (2007). A Comparison of Usability Evaluation Methods for Child Participants in a School Setting. IDC 2007, Aalborg, Denmark, ACM Press.

Fisher, E. (1994). "Joint composition at the computer: Learning to talk about writing." Computers and Composition 11: 251 - 262.

Gilutz, S. and J. Nielsen (2002). Usability of Websites for Children: 70 Design Guidelines. Freemont, CA, Nielsen Norman Group: 1 - 127.

Haas, C. and J. R. Hayes (1986). "What did I just say? Reading problems in writing with the machine." Research in the teaching of English 20(1): 22 - 35. 
Hanna, L., D. Neapolitan, et al. (2004). Evaluating Computer Game Concepts with Children. IDC2004, Maryland, US, ACM Press.

Hanna, L., K. Risden, et al. (1997). "Guidelines for usability testing with children." Interactions 1997(5): 9-14.

Harris, R., J. Rick, et al. (2009). Around the table: are multiple-touch surfaces better than single-touch for children's collaborative interactions?. CSCL'09. Hassenzahl, M., A. Platz, et al. (2000). Hedonic and Ergonomic Quality Aspects Determine a Software's Appeal. CHI2000, The Hague, Amsterdam, ACM Press.

Hourcade, J. P., B. B. Bederson, et al. (2004). "Differences in pointing task performance between preschool children and adults using mice. ." ACM Transactions on Computer Human Interaction 11(4): 357 - 386

Jacobson, F. F. (1995). "From Dewey to Mosaic :considerations in interface design for children." Internet Research, 5(2): 67 - 73.

Joiner, R., D. Messer, et al. (1998). "It is best to point for young children: A comparison of children's pointing and dragging." Computers in Human Behavior 14: 513 - 529.

Kafai, Y. B., Ed. (1990). From Barbie to Mortal Kombat, Gender and Computer Games, MIT Press. Kelly, S. R., E. Mazzone, et al. (2006). Bluebells: A Design Method for Child-Centred Product Development. NordiChi 2006, Oslo, ACM Press. Kersten-Tsikalkina, M. and M. Bekker (2001). Evaluating usability and pleasure of children's products. International Conference on Affective Human Factors Design, Singapore.

Khaled, R., P. Barr, et al. (2009). Let's clean up this mess: exploring multi-touch collaborative play. . CHI '09, ACM Press.

Klein, P. S., O. Nir-Gal, et al. (2000). "The use of computers in kindergarten, with or without adult mediation; effects on children's cognitive performance and behavior." Computers in Human Behavior 16(6): 591 - 608.

Krasnor, L. R. and D. J. Pepler (1980). "The study of children's play: Some suggested future directions." New Directions for Child and Adolescent Development 1980(9): 85 - 95.

Marco, J., E. Cerezo, et al. (2009). Bringing tabletop technologies to kindergarten children. BCS-HCl2009, Cambridge, UK, ACM Press.

Markopoulos, P., W. Barendregt, et al. (2005). The Parent Evaluator Method. Workshop on Child Computer Interaction:Methodological Issues, Rome.

Markopoulos, P. and M. Bekker (2002). Usability testing with children subjects: comparing Usability Testing methods. Interaction Design and Children, Eindhoven

Markopoulos, P., J. Höysniemi, et al. (2005). Child Computer Interaction: Methodological Research. Interact 2005, Rome, Italy.
Markopoulos, P., J. C. Read, et al. (2008). Evaluating Interactive Products for and with Children. San Fransisco, Morgan Kaufmann.

Marti, P., A. Pollini, et al. (2009). Creative interactive play for disabled children. IDC'09, Como, Italy.

Mills, C. B. and L. J. Weldon (1987). "Reading Text from Computer Screens." ACM Computing Surveys 19(4): 329 - 358

Mostow, J., A. G. Hauptmann, et al. (1995). Demonstration of a Reading Coach that Listens. UIST '95, Pittsburgh, PA, ACM Press.

Newell, A. F., L. Boothe, et al. (1992). "Increasing literacy levels by the use of linguistic prediction." Child Language Teaching and Therapy 8: 138 187.

Paive, A., R. Chaves, et al. (2003). SenToy: a Tangible Interface to Control the Emotions of a Synthetic Character. AAMAS '03.

Papert, S. (1980). Mindstorms, Children, Computers and Powerful Ideas. Great Britain, Basic Books.

Pardo, S., F. Vetere, et al. (2006). Teachers' Involvement in usability testing with children. IDC 2006, Tampere, Finland, ACM Press.

Pares, N., J. Durany, et al. (2005). Massive flux design for an interactive water installation: WATER GAMES. ACE05, Valencia, Spain, ACM Press.

Read, J. C. (2004). "Designing Multimedia Applications for Children." Comp@uclan 3.

Read, J. C. (2005). "The ABC of CCl." Interfaces 62: 8 - 9 .

Read, J. C. (2008). Is what you see what you get? Children, Technology and the Fun Toolkit. VUUM 2008, Rejkyavik, Iceland, ESF.

Read, J. C., P. Gregory, et al. (2002). An Investigation of Participatory Design with Children Informant, Balanced and Facilitated Design. Interaction Design and Children, Eindhoven, Shaker Publishing.

Read, J. C., S. J. MacFarlane, et al. (2001). Can Natural Language Recognition Technologies be used to enhance the Learning experience of Young Children? Computers and Learning, Warwick, UK.

Read, J. C., S. J. MacFarlane, et al. (2002). Endurability, Engagement and Expectations: Measuring Children's Fun. Interaction Design and Children, Eindhoven, Shaker Publishing.

Resnick, M. (1991). "MultiLogo: A Study of Children and Concurrent Programming." Interactive Learning Environments 1(3): 158 - 170.

Revelle, G., A. Fenwick-Naditch, et al. (2010). CHI 2010 special interest group: creating prosocial media for children. CHI 2010, Atlanta, ACM Press.

Revelle, G. and E. Strommen (1990). "The effects of practice and input device used on young children's computer control." Journal of Computing in Childhood 2(1): 33 - 41

Robertson, J. (2002). Experiences of designing with children and teachers in the StoryStation Project. IDC 2002, Eindhoven. 
Robins, B., K. Dautenhahn, et al. (2008). Behaviour delay and robot expressiveness in child-robot interactions: a user study on interaction kinesics. 3rd ACM/IEEE international conference on Human robot interaction, The Netherlands, ACM Press.

Rode, J. A. (2009). Digital parenting: designing children's safety. . BCS-HCl '09, Cambridge, UK, British Computer Society.

Rode, J. A., M. Stringer, et al. (2003). Curriculum Focused Design. IDC 2003, Preston, ACM Press.

Rogers, Y., M. Scaife, et al. (2002). "Conceptual Framework for Mixed Reality Environments: Designing Novel Learning Activities for Young Children. ." Presence Teleoperators and Virtual Environments 11(6).

Sedighian, K. and A. S. Sedighian (1997). Aesthetic Response: Children's Reactions to Color and Graphics in Educational Software. EDMEDIA97: World Conference on Educational Multimedia and Hypermedia, Calgary.

Selwyn, N. (2003). "Schooling the mobile generation: the future for schools in the mobilenetworked society." British Journal of Education 24(2): 131 - 144.

Siek, K. A., Y. Rogers, et al. (2005). Fat Finger Worries: How Older and Younger Users Physically Interact with PDAs. Interact 2005, Rome, IFIP.

Sluis-Thiescheffer, W., T. Bekker, et al. (2007). Comparing Early Design Methods for Children. IDC 2007, Aalborg, Denmark, ACM Press.

Soloway, E., M. Guzdial, et al. (1994). "Learnercentered design: the challenge for $\mathrm{HCl}$ in the 21st century." Interactions 1(2): 26 - 48.

Stromberg, H., A. Vaatanen, et al. (2002). A group game played in interactive virtual space. DIS2002, London, UK, ACM Press.
Strommen, E. (1994). Children's use of mousebased interfaces to control virtual travel. $\mathrm{CHI}$ '94, Boston, MA, ACM Press.

Taxen, G., A. Druin, et al. (2001). "KidStory: a technology design partnership with children." Behaviour and Information Technology 20(2): 119 125.

Teh, J. K., A. D. Cheok, et al. (2008). Huggy Pajama: a mobile parent and child hugging communication system. 7th international Conference on interaction Design and Children Chicago, Illinois, ACM, ACM Press.

Wakkary, R. and M. Hatala (2006). ec(h)o: Situated Play in a Tangible and Audio Museum Guide. DIS 2006, Pennsylvania, USA, ACM Press.

Xu, D., J. C. Read, et al. (2007). Evaluation of Tangible User Interfaces (TUIs) for and with Children - Methods and Challenges. HCll 2007, Beijing, Springer.

Yarosh, S., Y. C. Chew, et al. (2009). " Supporting Parent-Child Communication in Divorced Families." International Journal of Human Computer Studies 67(2): 192 - 203.

Zaman, B. and V. V. Abeele (2010). Laddering with young children in User experience evaluations: theoretical groundings and a practical case. IDC '10, ACM Press.

Zuckerman, O., N. Parés, et al. (2008). Designing interactive environments for outdoors gaming and play. $\mathrm{CHI}, \mathrm{ACM}$. 